\title{
3D Printing Technology with Plastic Materials for Hip Implant Master Patterns Manufacturing
}

\author{
ALEKSANDAR RAJIC ${ }^{1 *}$, ELEONORA DESNICA ${ }^{2}$, IVAN PALINKAS ${ }^{2}$, DORIAN NEDELCU ${ }^{3}$, LJUBICA LAZIC VULICEVIC ${ }^{1}$ \\ ${ }^{1}$ Technical College of Applied Sciences, Djordja Stratimirovica 23, 23000 Zrenjanin, Republic of Serbia \\ ${ }^{2}$ University of Novi Sad, Technical Faculty "Mihajlo Pupin", Djure Djakovica bb, 23000 Zrenjanin, Republic of Serbia \\ 3"Eftimie Murgu" University of Resita, 1-4 Traian Vuia Sq., 320085, Resita, Romania
}

This paper describes a hip implant model designed to assess the Fused Deposition Modeling (FDM) process for manufacturing investment casting master patterns. In addition, an indirect approach toward manufacturing master pattern via silicone rubber moulding in conjunction with $3 D$ Printing process manufactured hip implant master pattern has been investigated. The dimensional accuracies of the manufactured AM master patterns and the wax pattern are presented. Finally, cost and lead time comparisons carried out between FDM ABS pattern manufacturing, indirect pattern manufacturing via silicone rubber moulding and conventional pattern manufacturing by metal mould are also presented.

Keywords: 3D Printing, ABS material, silicone rubber moulding, hip implant, master pattern

The development of CAD/CAM technologies, and later Additive Manufacturing (AM) technology, enabled the production of orthopaedic implants of highly complex structures and shapes. Along with them, different approaches to the design of orthopaedic implants have emerged as well as new possibilities for their manufacturing [1-4]. Finding the right design and procedures for making orthopaedic implants is one of the priorities of current research in the field of Additive Manufacturing technologies application in medicine. Increasing quality, productivity, profitability and conformity to ecological criteria require further rationalization and optimization of conventional technologies for the production of orthopaedic hip implants through the development and application of new technologies [5-7]. This also applies to investment casting foundries which have the ambition to produce demanding, complex and high quality castings for the use in medicine. Their development requires appropriate innovations, application of the latest technological knowledge and information technology [8-13].

The term Rapid Investment Casting (RIC) represents the employment of AM technologies in investment casting. The designing costs as well as the metal tools manufacturing costs for the development of master patterns can be overcome by applying AM technologies. The employment of AM technologies also results in shorter casting time while providing the same quality. AM has been particularly effective in prototyping, as well as in single and smallscale productions. A large number of cost-effective solutions for investment casting of orthopaedic implants employing additive technologies have been reported in the literature so far [2, 6, 7, 13-17].

Harrysson et al. [18] proposed a computer-aided methodology for customized knee implants manufacturing. The process involves the integration of technologies such as Computed Tomography (CT), image processing, Stereolitography (SLA) process, Room Temperature Vulcanizing (RTV) and investment casting, in the design and manufacturing of a near optimal fit between the patient's bone and the implant component.

Maji et al. [19] reported the possibility to use RIC technology to obtain craniofacial implants manufactured from bio-compatible materials. The research was conducted using the following process series: 3D CAD - Rapid Prototyping - Rapid Tooling - Investment casting. Aluminium craniofacial implants were manufactured and since aluminium is not a bio-compatible material, further researches will include application of this kind of materials.

Horacek et al. [20] describe the application of AM technologies and the investment casting process in the production of knee prostheses. The ABS master pattern of the knee implant was manufactured using the FDM process. After the manufacturing of the master pattern, the technology of vacuum casting in a silicone rubber (RTV) mould was applied, which produced a wax pattern of the knee implant. The obtained wax pattern was later applied in the investment casting process. The authors conclude that using the approach which integrates processes such as FDM, RTV and investment casting, it is possible to produce knee prostheses, whose mechanical characteristics and material properties, can compete with those of the conventional knee prostheses.

Ramos et al. [21] showed the development of technical procedure for hip prototype implant manufacturing. The authors reported that the vacuum casting technique combined with RTV procedure was suitable for master patterns manufacturing for investment casting of some prototypes. They concluded that the tested technical procedure was acceptable for manufacturing of many cheap metal prototypes with excellent characteristics and functionality.

*email: aleksandar.rajic@vts-zr.edu.rs 
A total hip replacement (THR) is a surgical procedure whereby the diseased connective tissue and the bone of the hip joint are surgically replaced with artificial materials. During hip replacement surgery, the head of the femur is removed and replaced with a metal ball set on a stem. The stem is inserted into the canal of the femur. It may be fixed in place with cement, or the stem may be designed for placement without bone cement. The socket is sanded down to healthy bone, and a plastic cup or socket is held in place with screws and/or bone cement [22]. Metal orthopaedic implants made of meltable models are Austin Moore hip prostheses stem for cemented implantation and Figure 1 shows the tool for meltable-wax model and finished Austin Moore hip implant metal cast piece. The material used for metal implants is CoCrMo alloy.

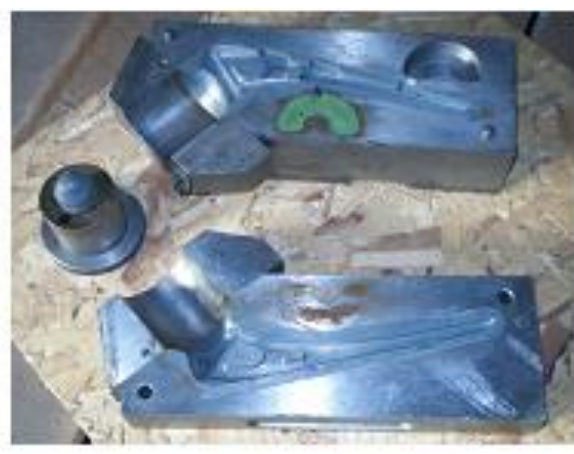

a)

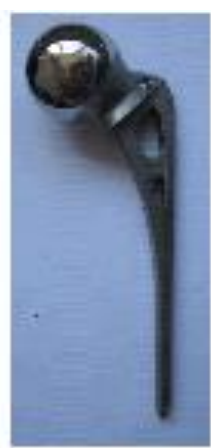

b)

Fig. 1. Tool for meltable implant model a) and finished hip implant metal cast piece b)

At the same time, a very strict certification regarding the material quality causes problems to foundries. Hip implants are produced in different sizes, for the left and right hip separately. Manufacturers are trying to satisfy each individual patient's needs at a surgery. The focus of the work presented in this paper is on the manufacturing of ABS hip implant master pattern using the FDM technique and the manufacturing of silicone rubber mould via 3D printing technique in conjunction with an 3DP-fabricated hip implant master pattern. Two different AM approaches were analysed and compared regarding consumption and characteristics of the applied plastic materials, time and characteristics of the printing process.

\section{Experimental part}

The study flow chart of this work is shown in Figure 2. The first stage in the research was the creation of a 3D CAD model of the hip implant in the SolidWorks software package. The geometry of the hip implant is presented in Figure 3 a). The CAD geometry of the hip implant was exported on an STL file resulting in 9580 triangles, as shown in Figure $3 \mathrm{~b}$ ). In the second phase of the research, two different AM approaches to the design of master patterns were applied: direct manufacturing of the ABS hip implant pattern using FDM technology and indirect manufacturing of the wax implant hip pattern by injection moulding in a silicone rubber mould.

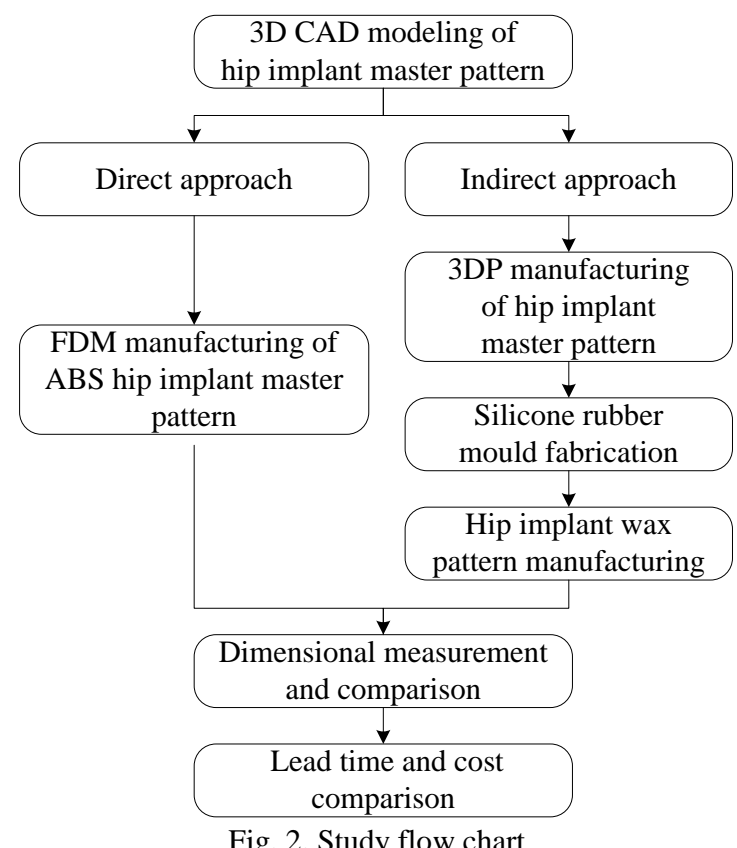


In the third phase, control measurements were conducted and the accuracy of the AM and wax pattern of the hip implant was determined. In the fourth phase, the time and the costs of developing a master pattern by direct and indirect approach were analysed.

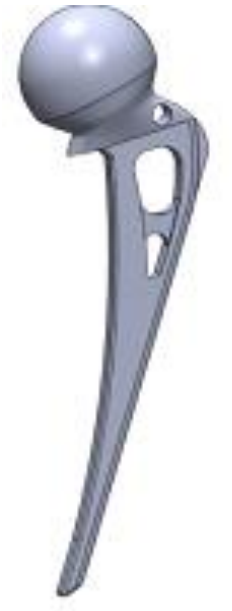

a)

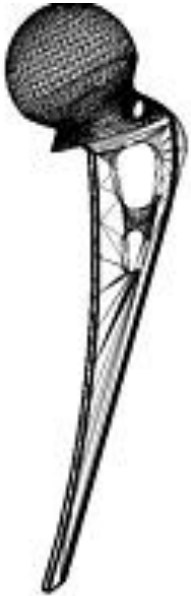

b)

Fig. 3. Visual display of the hip implant model: SolidWorks model a) and STL model (9580 triangles) b) [22]

Direct approach to manufacturing of ABS master pattern of hip implant by FDM technology

The thermoplastic ABS material was used on the Stratasys Prodigy Plus FDM system (Rapid Prototyping Laboratory, Czech Technical University in Prague, Czech Republic) to fabricate the pattern with FDM technology. The pattern of the hip implant was made with a hollow internal structure, thust fulfilling one of the requirements for making master patterns by investment casting, namely, the small volume mass. The hip model was made as a quasihollow pattern, i.e. with internal mesh structure and wall thickness between $1.5 \mathrm{~mm}$ and $1.9 \mathrm{~mm}$. In Figure 4 the internal structure of the model (or the movement of the nozzle) can be observed when applying the material.

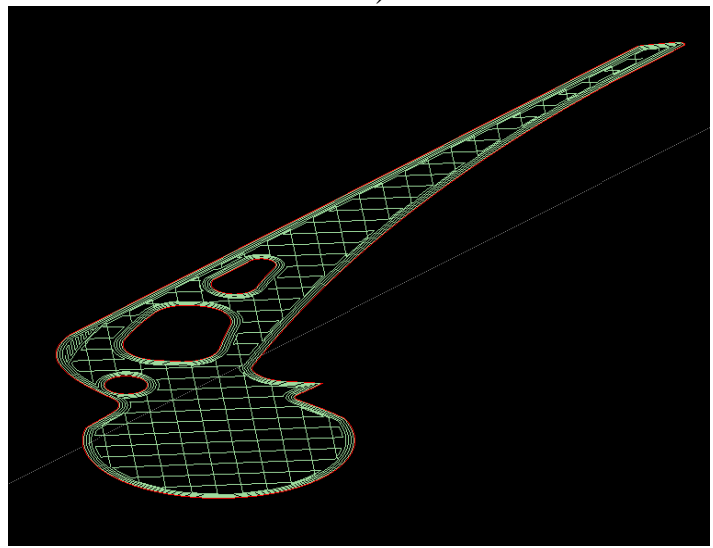

Fig. 4. Tool movement when forming a representative layer of the ABS model

The model was made with a thickness of $0.1778 \mathrm{~mm}$, and the build time was 7 hours. Table 1 shows the most important parameters of the hip implant design process used in the experiment.

Table 1

FDM PROCESS PRINT PARAMETERS

\begin{tabular}{|l|l|}
\hline Parameter & Hip implant pattern \\
\hline Part volume & $69.986 \mathrm{~cm}^{3}$ \\
\hline Max manufacturing height & $48.36 \mathrm{~mm}$ \\
\hline Layer thickness & $0.1778 \mathrm{~mm}$ \\
\hline Infill tool path width & $0.3798 \mathrm{~mm}$ \\
\hline Conture tool path width & $0.4298 \mathrm{~mm}$ \\
\hline Number of layers & 272 \\
\hline Model material (ABS) & $32.356 \mathrm{~cm}^{3}$ \\
\hline Support material (WaterWorks) & $18.322 \mathrm{~cm}^{3}$ \\
\hline Manufacturing time & 7 hours \\
\hline
\end{tabular}


Preparation of the model for printing was realized in the software package Stratasys Insight used by FDM systems. In Figure 5 the ABS model of the Austin Moore hip implant with a support structure is shown.

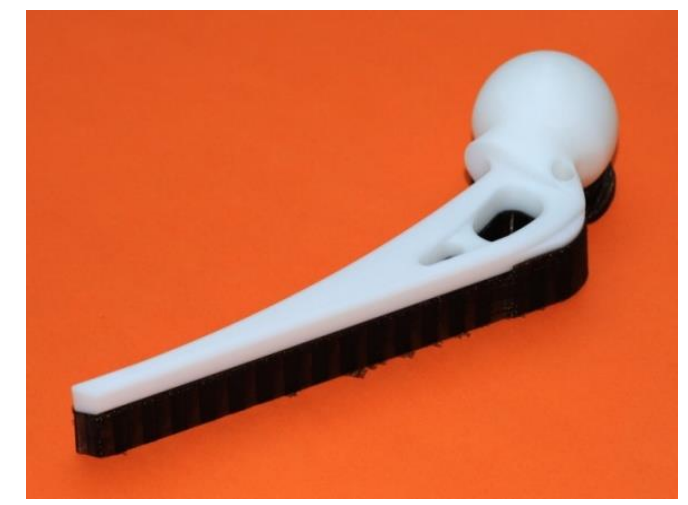

Fig. 5. ABS pattern of hip implant with supporting structure

Indirect approach to manufacturing of wax hip implant pattern by injection moulding in silicone rubber mould

The master pattern of the hip implant was made on the 3D Printing System Spectrum Z510 ("3D Svet" Belgrade, Serbia) using the high quality powder composite ZP151 with the binder ZB60. The infiltration material was epoxy resin S5000. The thickness of the layer was $0.0889 \mathrm{~mm}$, while the time required to produce the hip implant was 2.5 hours.

Two-component silicone rubber Hydrosil 1:1 SILADENT (Dr. Bohme \& Schops GmbH, Germany) suitable for moulding ceramic, gypsum, wax, polyester and epoxy resin was used to make moulds for wax hip implants patterns. One of the basic applications of this silicone rubber is in dentistry and orthodontics. This silicone rubber vulcanizes at room temperature (RTV). Hydrosil material working and curing time at $23^{\circ} \mathrm{C}$ was approximately 35 minutes and the time to mould disassembly was 24 hours at room temperature. Silicone can cure at room temperature, but it is recommended to dry at about $40^{\circ} \mathrm{C}$ for 4 to 8 hours, so that the master pattern will not expand. Mould material characteristics such as durability and mould life span depend largely on the mass ratio of the components when mixed [22-24]. Table 2 gives the characteristics of the Hydrosil silicone.

Table 2

HYDROSIL MATERIAL CHARACTERISTICS [25]

\begin{tabular}{|l|l|}
\hline Characteristics & Value \\
\hline $\begin{array}{l}\text { Mixing ratio } \\
\text { A (white) : B (green) }\end{array}$ & $1: 1$ \\
\hline Mixing under vacuum & 40 sec. \\
\hline Working time at $23^{\circ} \mathrm{C}$ & $4-5$ min \\
\hline Curing time at $23^{\circ} \mathrm{C}$ & approx. $30 \mathrm{~min}$ \\
\hline Tensile strength & approx. $2.6 \mathrm{MPa}$ \\
\hline Elongation at break & approx. $400 \%$ \\
\hline Tear strength & approx. $7.0 \mathrm{~N} / \mathrm{mm}$ \\
\hline Shore A hardness & $22-24$ \\
\hline Colour & green \\
\hline Price for $2 \times 1 \mathrm{~kg}$ & $57 €$ \\
\hline
\end{tabular}

In Figure 6 a silicone mould for making wax hip implant patterns is shown. The red lines represent the dividing lines and the path of the mould cut. When cutting the mould, the box and the parts of the pouring system must be removed. If the separation line is marked in the previous steps, it is necessary to cut the mould along the line with a scalpel or a special knife. Proper cutting along the line is not so important since the uneven parting surface makes it easy to assemble the mould. 


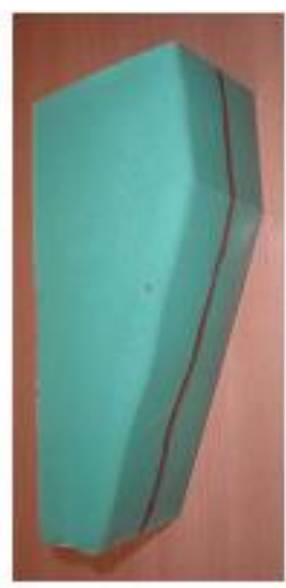

a)

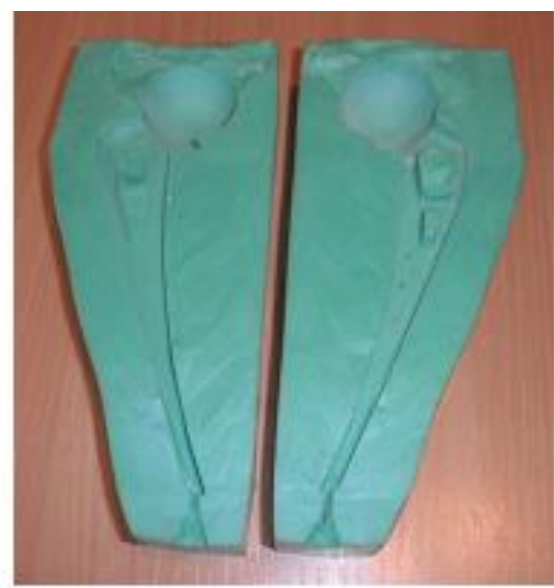

b)

Fig. 6. Silicone mould for making wax hip implant patterns before a) and after separation b)

After the mould was made, a wax injection process followed using the injector nozzle with the following technical characteristics: vessel capacity - 2 liters, heater power $-500 \mathrm{~W} / 220 \mathrm{~V}$, operating temperature $-75^{\circ} \mathrm{C}\left(\max .100^{\circ} \mathrm{C}\right.$ ). The wax used to make the model of orthopaedic implants was SRS 863 Pink Wax (SRS Limited, UK) with good general characteristics, a very low shrinkage percentage and a high elasticity. It is characterized by its extremely glossy surface. The injection temperature of this wax was $72^{\circ} \mathrm{C}-74^{\circ} \mathrm{C}$. The price of the 863 Pink Wax was $€ 11.15 /$ $\mathrm{kg}$ [22]. Figure 7 shows a silicone rubber mould with a wax hip implant pattern made for research purposes. Applied master 3DP pattern is also shown.

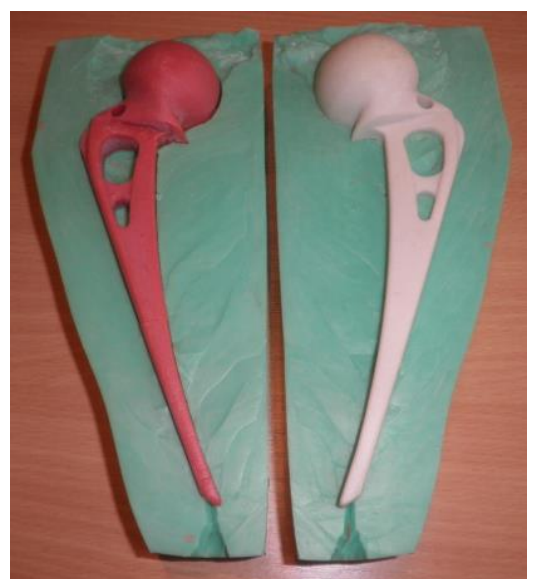

Fig. 7. Silicone rubber mould, wax pattern (left) and 3DP master pattern (right) of hip implant Austin Moore

\section{Results and discussions}

The accuracy of fabricated AM and wax patterns of hip implants was determined by measuring the critical dimensions and comparing them with the corresponding nominal measures. The measurements were carried out using a digital calliper (Figure 8) with measuring range from 0 to $150 \mathrm{~mm}$ and with accuracy of $0.01 \mathrm{~mm}$. Each critical dimension was measured three times.

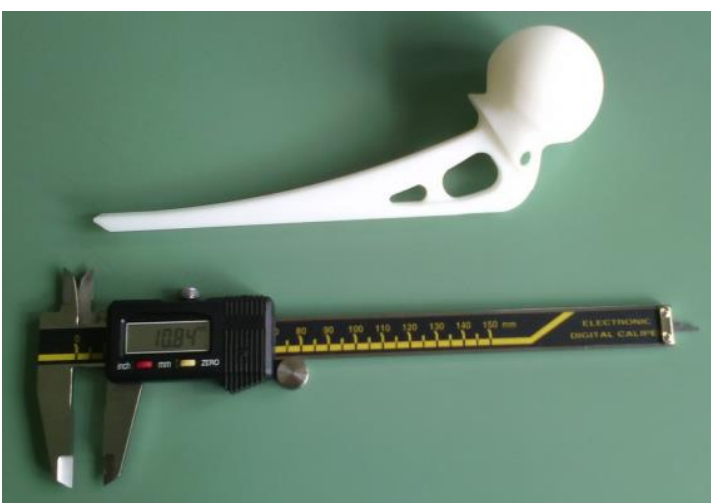

Fig. 8. Digital calliper and ABS pattern of hip implant 
The quantitative analysis of the results, which are an indicator of accuracy in the procedure of making orthopaedic hip implants, included the analysis of the arithmetic mean deviation of the AM and the wax pattern measured values relation to the initial CAD models. The mean or arithmetic mean (denoted by $\bar{x}$ ) was calculated by dividing the sum of all measurements by the number of measurements:

$$
\bar{x}=\frac{\sum x_{i}}{N}
$$

The mean deviation (denoted by $S_{0}$ ) was calculated using the equation:

$$
S_{0}(\mathrm{~mm})=\bar{x}(\mathrm{~mm})-\text { Nominal dimension }(\mathrm{mm})
$$

The percentage deviation or accuracy was calculated using the equation:

$$
\operatorname{Accuracy}(\%)=\left[\frac{\text { Average deviation }(\mathrm{mm})}{\text { Nominal dimension }(\mathrm{mm})}-1\right] \cdot 100
$$

In Figure 9 the critical dimensions of the AM pattern and the wax pattern of the hip implant were analysed. The dimension L4* was occluded and therefore represented by a dashed line in the figure on the right.

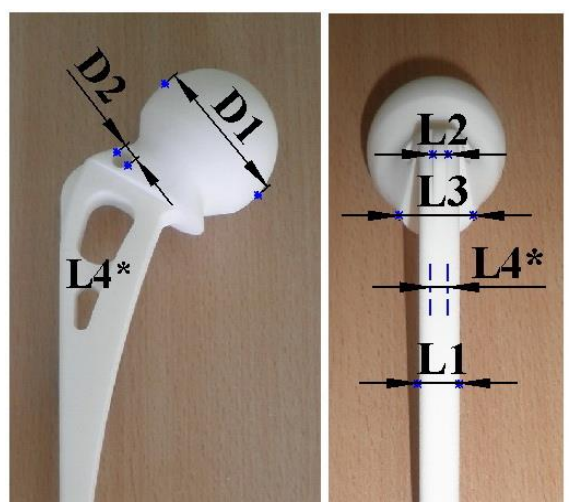

Fig. 9. Critical dimensions of the hip implant pattern

Table 3 shows the critical measures of the CAD model, 3DP and wax pattern, their respective measured values, the corresponding mean values of the measured dimensions, the mean deviations, and also expressed as percentages and dimensional accuracy.

\begin{tabular}{|c|c|c|c|c|c|c|c|}
\hline \multirow{2}{*}{\multicolumn{2}{|c|}{ CAD model [mm] }} & $\mathrm{L} 1$ & $\mathrm{~L} 2$ & L3 & L4 & D1 & D2 \\
\hline & & 10.09 & 3.36 & 23.07 & 6.73 & 42.75 & 6.65 \\
\hline \multirow{4}{*}{$\begin{array}{l}\text { FDM } \\
\text { pattern } \\
{[\mathrm{mm}]}\end{array}$} & Measurement I & 10.22 & 3.42 & 22.89 & 6.74 & 42.61 & 6.46 \\
\hline & Measurement II & 10.22 & 3.44 & 22.95 & 6.74 & 42.59 & 6.54 \\
\hline & Measurement III & 10.22 & 3.42 & 22.90 & 6.76 & 42.61 & 6.50 \\
\hline & Mean values & 10.22 & 3.43 & 22.91 & 6.75 & 42.60 & 6.50 \\
\hline \multicolumn{2}{|c|}{ Mean deviation [mm] } & 0.13 & 0.07 & -0.16 & 0.02 & -0.15 & -0.15 \\
\hline \multicolumn{2}{|c|}{ Percentage representation [\%] } & 1.2884 & 2.0833 & 0.6935 & 0.4237 & 0.3508 & 2.2556 \\
\hline \multicolumn{2}{|c|}{ Average accuracy [\%] } & \multicolumn{6}{|l|}{1.1823} \\
\hline \multirow{4}{*}{$\begin{array}{l}\text { 3DP } \\
\text { pattern } \\
{[\mathrm{mm}]}\end{array}$} & Measurement I & 10.64 & 3.52 & 23.28 & 6.69 & 42.56 & 6.44 \\
\hline & Measurement II & 10.62 & 3.51 & 23.23 & 6.68 & 42.52 & 6.42 \\
\hline & Measurement III & 10.66 & 3.58 & 23.22 & 6.66 & 42.57 & 6.47 \\
\hline & Mean values & 10.64 & 3.54 & 23.24 & 6.68 & 42.55 & 6.44 \\
\hline \multicolumn{2}{|c|}{ Mean deviation [mm] } & 0.55 & 0.18 & 0.17 & -0.05 & -0.20 & -0.21 \\
\hline \multicolumn{2}{|c|}{ Percentage representation [\%] } & 5.4509 & 5.3571 & 0.7369 & 0.7429 & 0.4678 & 3.1579 \\
\hline \multicolumn{2}{|c|}{ Average accuracy [\%] } & \multicolumn{6}{|l|}{2.6523} \\
\hline
\end{tabular}

Table 3

DIMENSION COMPARISON OF FDM, 3DP AND WAX PATTERN WITH CAD MODEL OF HIP IMPLANT 


\begin{tabular}{|c|c|c|c|c|c|c|c|}
\hline \multirow{4}{*}{$\begin{array}{c}\text { Wax } \\
\text { pattern } \\
{[\mathrm{mm}]}\end{array}$} & Measurement I & 10.80 & 3.48 & 23.54 & 7.14 & 41.74 & 6.26 \\
\hline & Measurement II & 10.78 & 3.50 & 23.54 & 7.16 & 41.75 & 6.31 \\
\hline & Measurement III & 10.78 & 3.52 & 23.56 & 7.15 & 41.74 & 6.34 \\
\hline & Mean values & 10.79 & 3.50 & 23.55 & 7.15 & 41.74 & 6.30 \\
\hline \multicolumn{2}{|c|}{ Mean deviation [mm] } & 0.70 & 0.14 & 0.48 & 0.42 & -1.01 & -0.35 \\
\hline \multicolumn{2}{|c|}{ Percentage representation [\%] } & 6.9376 & 4.1667 & 2.0806 & 6.2407 & 2.3626 & 5.2632 \\
\hline \multicolumn{2}{|c|}{ Average accuracy [\%] } & \multicolumn{6}{|c|}{4.5085} \\
\hline
\end{tabular}

The diagram in Figure 10 which shows a comparative analysis of the accuracy of AM and wax patterns of hip implants, suggests that 3DP process had lower accuracy then FDM process. The indirect approach to developing a wax hip implant pattern has proven to be the least accurate, due to several factors.

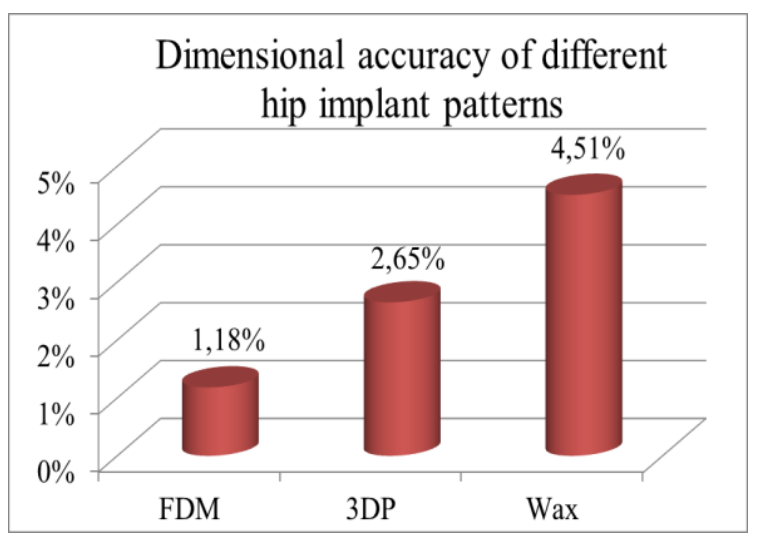

Fig. 10. Dimensional accuracy of FDM, 3DP and wax hip implant patterns

It is important to note that this percentage of accuracy can be significantly improved by correcting the scaling factor. Since the experimental sample of the wax pattern is intended solely for research purposes and not for casting implants, wax and silicone shrinkage factors have not been considered. A comparison of the mean values of the critical dimensions of the wax pattern and the 3DP master pattern (Table 4) reveals a non-uniform dimension change as a consequence of thermal shrinkage. The dimensional deviations of the wax pattern are due to the accuracy of the 3DP master pattern, the silicone rubber mould and the wax injection process.

Table 4

MEAN VALUE COMPARISON OF THE WAX AND 3DP HIP IMPLANT PATTERN

\begin{tabular}{|l|c|c|c|c|c|c|}
\hline & L1 & L2 & L3 & L4 & D1 & D2 \\
\hline 3DP pattern [mm] & 10.64 & 3.54 & 23.24 & 6.68 & 42.55 & 6.44 \\
\hline Wax pattern [mm] & 10.79 & 3.50 & 23.55 & 7.15 & 41.74 & 6.30 \\
\hline Mean deviation [mm] & 0.15 & -0.04 & 0.31 & 0.47 & -0.81 & -0.14 \\
\hline Percentage representation [\%] & 1.4098 & 1.1299 & 1.3339 & 7.0359 & 1.9036 & 2.1739 \\
\hline Average accuracy [\%] & $\mathbf{2 . 4 9 7 9}$ & & &
\end{tabular}

Expansions of $1.40 \%, 1.33 \%$ and $7.03 \%$ were observed for certain critical dimensions L1, L3 and L4, while shrinkages of $1.12 \%, 1.90 \%$ and $2.17 \%$ were observed for dimensions L2, D1 and D2. The average accuracy of the wax pattern compared to the 3DP master pattern is $2.49 \%$. By neglecting the least critical dimension of L4, which is also the thinnest part of the hip implant master pattern, the average accuracy is $1.59 \%$.

Tables 5 and 6 show a comparison of the time and cost required to fabricate master hip implant pattern by direct approach, indirect approach (injection moulding in silicone rubber moulds) and conventional wax injection moulding into a metal tool. Lead times required to fabricate master patterns were 49 hours for a direct approach, 71 hours for an indirect approach, and 431 hours for a conventional procedure. Regarding the costs of a hip implant master pattern making, they were $€ 110$ for direct access, $€ 180$ for indirect access and about $€ 2000$ for the conventional wax injection moulding process. It is important to note that the analysis was conducted to fabricate a single pattern of a hip implant. CNC metal mould life span is up to 100,000 wax patterns, while silicone rubber moulds have a life span of 100-300 wax patterns. 
Table 5

COMPARISON OF HIP IMPLANT MASTER PATTERNS MANUFACTURING TIME

\begin{tabular}{|c|c|c|c|c|c|}
\hline $\begin{array}{l}\text { FDM ABS pattern } \\
\text { manufacturing }\end{array}$ & & $\begin{array}{c}\text { Indirect pattern } \\
\text { manufacturing via silicone } \\
\text { rubber moulding }\end{array}$ & & $\begin{array}{c}\text { Conventional } \\
\text { pattern } \\
\text { manufacturing by } \\
\text { metal mould }\end{array}$ & \\
\hline $\begin{array}{c}\text { CAD master } \\
\text { pattern modeling }\end{array}$ & $40 \mathrm{~h}$ & $\begin{array}{l}\text { CAD modeling of 3DP master } \\
\text { pattern }\end{array}$ & $40 \mathrm{~h}$ & CAD tool modeling & $80 \mathrm{~h}$ \\
\hline FDM process preparation & $1 \mathrm{~h}$ & Process preparation & $1 \mathrm{~h}$ & $\begin{array}{l}\text { CNC manufacturing } \\
\text { of metal mould for } \\
\text { master pattern }\end{array}$ & $350 \mathrm{~h}$ \\
\hline FDM pattern manufacturing & $7 \mathrm{~h}$ & $\begin{array}{l}\text { 3DP master pattern } \\
\text { manufacturing }\end{array}$ & $2.5 \mathrm{~h}$ & $\begin{array}{l}\text { Wax pattern manu- } \\
\text { facturing }\end{array}$ & $1 \mathrm{~h}$ \\
\hline \multirow[t]{5}{*}{ FDM pattern post processing } & \multirow[t]{5}{*}{$1 \mathrm{~h}$} & $\begin{array}{l}\text { 3DP master pattern post } \\
\text { processing }\end{array}$ & $1 \mathrm{~h}$ & & \\
\hline & & Preparation for pouring silicone & $1 \mathrm{~h}$ & & \\
\hline & & Silicone curing & $24 \mathrm{~h}$ & & \\
\hline & & $\begin{array}{c}\text { Silicone rubber mould post } \\
\text { processing }\end{array}$ & $0.5 \mathrm{~h}$ & & \\
\hline & & One wax pattern manufacturing & $1 \mathrm{~h}$ & & \\
\hline Overall time & $49 \mathrm{~h}$ & Overall time & $71 \mathrm{~h}$ & Overall time & $431 \mathrm{~h}$ \\
\hline
\end{tabular}

Table 6

HIP IMPLANT MASTER PATTERNS MANUFACTURING COST COMPARISON

\begin{tabular}{|c|c|c|c|c|c|}
\hline $\begin{array}{l}\text { FDM ABS pattern } \\
\text { manufacturing }\end{array}$ & & $\begin{array}{l}\text { Indirect pattern manufacturing } \\
\text { via silicone rubber moulding }\end{array}$ & & $\begin{array}{c}\text { Conventional pattern } \\
\text { manufacturing by metal } \\
\text { mould }\end{array}$ & \\
\hline $\begin{array}{l}\text { Manufacturing of one } \\
\text { FDM master pattern } \\
\text { (Quoted by a FDM } \\
\text { laboratory) }\end{array}$ & $110 €$ & $\begin{array}{l}\text { Manufacturing of one 3DP master } \\
\text { pattern (Quoted by a 3DP service) } \\
\text { Silicone rubber mould manu- } \\
\text { facturing } \\
\text { Manufacturing of one wax pattern }\end{array}$ & $\begin{array}{l}110 € \\
70 €\end{array}$ & $\begin{array}{c}\text { Aluminium mould + inserts } \\
\text { (Quoted by a local foundry) } \\
\text { Manufacturing of one wax } \\
\text { pattern }\end{array}$ & $\approx 2000 €$ \\
\hline Overall cost & $110 €$ & Overall cost & $180 €$ & Overall cost & $\approx 2000 €$ \\
\hline
\end{tabular}

\section{Conclusions}

In the experimental part of the research, the master patterns of various AM materials, 3DP high quality starchbased composite powder zp151 and FDM ABS polymer, were fabricated. The two-component silicone rubber Hydrosil mould was also made, while the SRS 863 Pink Wax material was used to make the wax pattern. The study showed that the critical dimensions of the wax hip implant pattern can be controlled to an accuracy of $2.49 \%$. The comparative analysis of the time and cost of manufacturing master patterns proved the advantage of an integrated system of rapid investment casting. 3D printing technology, may shorten the time of manufacturing a master pattern by $88.63 \%$ in direct, and $83.52 \%$ in indirect approach compared to conventional procedure. The cost savings of development of a master pattern range from $94.5 \%$ for direct approach to $91 \%$ for indirect approach. This analysis encompassed the prototypical manufacturing of the hip implant master pattern, and the results of the analysis confirm the advantages of manufacturing the master patterns by direct approach in the cases of prototype and single production. As for a small-scale production, up to several dozen pieces, the optimal choice would be to apply the indirect approach of master patterns manufacturing by injection moulding into silicone rubber moulds. In large-scale and mass-production cases, the advantage undoubtedly lies in conventional investment casting.

\section{References}

1.CHEAH, C.M., CHUA, C.K., LEE, C.W., FENG, C. and TOTONG, K., Rapid prototyping and tooling techniques: A review of applications for rapid investment casting. Int J of Adv Manuf Technol, 25, 2005, p. 308-320

2.CHHABRA, M., SINGH, R., Rapid casting solutions: A review, Rapid Prototyping Journal, Vol. 17, No. 5, 2011, p. 328-350

3.RAHMATI, S., ABBASZADEH, F., FARAHMAND, F., An improved methodology for design of custom-made hip prostheses to be fabricated using additive manufacturing technologies, Rapid Prototyping J., 18(5), 2012, p. 389-400

4.PATTNAIK, S., JHA, P.K. and KARUNAKAR, D.B., A review of rapid prototyping integrated investment casting processes, Proceeding of the Institution of Mechanical Engineers Part L: Journal of Materials and Design and Applications, Vol. 228 No. 4, 2013, p. 1-29 
5. RAJIC, A., DESNICA, E., STOJADINOVIC, S., NEDELCU, D., Numerical Simulation and Additive Manufacturing technology in design of knee implant patterns, Journal of Optoelectronics and Advanced Materials, Vol. 16, No. 9-10, 2014, p. 1180-1190

6.NEDELCU, D., BARA, A., PELLAC, A., SORIN L.B., A comparative study between the costs of polymer based rapid prototyping and steel based manufacture, Mat. Plast., 54, 2017, p. 443-446

7.HARRYSSON, O.L.A., CORMIER, D.R., MARCELLIN-LITTLE, D. and JAJAL, K., Direct fabrication of metal orthopedic implants using electron beam melting technology, Solid Freeform Fabrication Symposium, Austin, TX, USA, 2003, August 4-6

8.MAJI, P.K., BANERJEE, P.S., SINHA, A., Application of Rapid Prototyping and Tooling for fast development of patient-specific craniofacial implant: an Investigation Study, International Journal of Advanced Manufacturing Technology, Vol. 36, Issue. 5-6, 2008, p. 510-515

9.HORACEK, M., CHARVAT, O., PAVELKA, T., SEDLAK, J., MADAJ, M., NEJEDLY, J., DVORACEK, J., Medical implants by using RP and investment casting technologies, China Foundry, Vol. 8, No. 1, 2011, p. 107-111

10.RAMOS, A.M.D.M., SIMOES, J.A., CAD-CAM-RTV - lost-wax casting technology for medical implants, Rapid Prototyping Journal, 15(3), 2009, p. 211-215

11.RAJIC, A., Application of Additive Manufacturing Technologies in Investment Casting of Orthopaedic Implants, Ph.D. Thesis, University of Novi Sad, Tehnical Faculty "Mihajlo Pupin” Zrenjanin, Republic of Serbia, 2015

12.KUO, C.C., SHI, Z.S., Fabrication of a high precision silicone rubber mold for replicating wax patterns of cylinder heads, Indian Journal of Engineering and Materials Sciences, 19(3), 2012, p. 157-162

13.SINGH, S., SINGH, R., Fused deposition modelling based rapid patterns for investment casting applications: a review, Rapid Prototyping Journal, Vol. 22 No. 1, 2016, p. 123-143

14.*** SILADENT Dr. Böhme \& Schöps GmbH, Product catalogue, 2019

Manuscript received: 25.09.2019 